\title{
Edukasi Anti Penyalahgunaan Obat Kepada Siswa SD Di Kota Palu Melalui Kuartet Media Kartu
}

\section{(Education of Anti-drug Abuse for Elementary School Students in Palu Citythrough Quartet Card Media)}

\author{
Hannan $^{1,2, *}$, Pratiwi Wikaningtyas ${ }^{1}$ dan I Ketut Adnyana ${ }^{1}$ \\ ${ }^{1}$ Program Studi Magister Farmasi, Sekolah Farmasi, Institut Teknologi Bandung, Bandung, Indonesia, 40132 \\ ${ }^{2}$ Balai POM di Palu, Palu, Indonesia, 94111
}

\begin{tabular}{l} 
Article Info: \\
Received: 10 February 2019 \\
in revised form: 6 March 2019 \\
Accepted: 19 March 2019 \\
Available Online: \\
\hline Keywords: \\
Innovation \\
Education \\
Anti-drug abuse \\
Quartet card \\
Elementary school students \\
\hline \\
Corresponding Author: \\
Hannan \\
Balai POM Di Palu, \\
94111, Palu, \\
Indonesia \\
Mobile : 085255123549 \\
Email: hannanbmq@gmail.com
\end{tabular}

\begin{abstract}
Cases of illegal drugs and drug abuse in the elementary school community in Indonesia is increasingly massive and alarming. An innovation to protect elementary school students from that situation is through the colaboration of academics from Bandung Institute of Technology with FDA in Palu in the form education of anti-drug abuse for elementary school students through quartet card media. The aim of the study was to determine the effect of the education on anti-drug abuse knowledge in fifth grade students in Palu City. The research method used pre-experimental design with the design of one group pretest-posttest on three elementary schools which were representatives of three ranks namely; good, quite good and not good based on the results of the Smart-Accurate Quiz FDA in Palu for elementary school level in 2017. The sampling technique used purposive sampling. Observation of knowledge of elementary students using questionnaires that have been tested for validity and reliability had been carried out. The pretest and posttest were conducted before and after education. The comparison of pretest and posttest data in each elementary school was analyzed using paired $\mathrm{T}$ test whereas for all elementary school data analyzed using the Wilcoxon test with hypotheses. There was an influence of anti-drug abuse education through quartet card media on anti-drug abuse knowledge in fifth grade students in Palu City. The results showed that there was an influence of education on anti-drug abuse knowledge in fifth grade students from elementary school representatives "good and quite good ranking" with p values of 0.005 and $p \leq 0.001$, while in elementary schools representatives "not good ranking", the education did not influence their knowledge with a $\mathrm{p}$ value of 0.149 . Analysis of the Wilcoxon test in all elementary schools showed a $p$ value $p \leq 0,001$, which meant that education had an influence on the knowledge of fifth grade students in elementary schools in Palu City.
\end{abstract}

Copyright (C) 2017 JFG-UNTAD This open access article is distributed under a Creative Commons Attribution (CC-BY-NC-SA) 4.0 International license.

How to cite (APA 6th Style):

Hannan, Wikaningtyas, P., \& Adnyana, IK. (2019). Edukasi Anti Penyalahgunaan Obat Kepada Siswa SD Di Kota Palu Melalui Media Kartu Kuartet. Jurnal Farmasi Galenika : Galenika Journal of Pharmacy, 5(1), 20-25. doi: 10.22487/j24428744.2019.v5.i1.11933 


\begin{abstract}
ABSTRAK
Peredaran obat ilegal dan penyalahgunaan obat pada komunitas Sekolah Dasar di Indonesia semakin masif dan memprihatinkan. Wujud inovasi untuk memproteksi siswa SD dari masalah tersebut yaitu melalui kolaborasi akademisi Institut Teknologi Bandung dengan profesional Balai POM di Palu berupa edukasi anti penyalahgunaan obat kepada siswa SD melalui media kartu kuartet. Tujuan penelitian untuk mengetahui pengaruh edukasi tersebut terhadap pengetahuan anti penyalahgunaan obat siswa kelas lima SD di Kota Palu. Metode penelitian menggunakan preexperimental design dengan rancangan one group pretest-posttest terhadap siswa pada tiga SD yang telah memenuhi kriteria inklusi dan eksklusi yang ditetapkan. Teknik pengambilan sampel menggunakan purposive sampling. Observasi pengetahuan siswa SD menggunakan kuesioner yang telah diuji validitas dan reliabilitasnya. Pretest dan posttest dilakukan sebelum dan setelah edukasi. Komparasi data pretest dan posttest pada masing-masing SD dianalisis menggunakan uji $\mathrm{T}$ berpasangan sedangkan untuk data seluruh SD dianalisis menggunakan uji Wilcoxon dengan hipotesis ada pengaruh edukasi anti penyalahgunaan obat melalui media kartu kuartet terhadap pengetahuan anti penyalahgunaan obat siswa kelas lima SD di Kota Palu. Hasil penelitian menunjukkan ada pengaruh edukasi terhadap pengetahuan anti penyalahgunaan obat pada siswa kelas lima dari SD perwakilan rangking baik dan cukup baik dengan nilai p masing-masing sebesar 0,005 dan $p \leq 0,001$, sedangkan pada SD perwakilan ranking kurang baik, edukasi tersebut tidak memberikan pengaruh terhadap pengetahuan mereka dengan nilai p sebesar 0,149. Analisis uji Wilcoxon pada seluruh SD menunjukkan nilai $\mathrm{p} \leq 0,001$ yang berarti edukasi memberikan pengaruh terhadap pengetahuan siswa kelas lima SD di Kota Palu.
\end{abstract}

Kata Kunci :Inovasi; Edukasi; Anti Penyalahgunaan Obat; Kartu Kuartet; Siswa SD.

\section{PENDAHULUAN}

Organisasi kejahatan menunjukkan eksistensi afiliasinya dengan perdagangan obat ilegal hampir di 100 tahun terakhir. Saat ini modus operasi mereka telah memiliki struktur yang sangat kompleks dan didukung instrumen-instrumen berteknologi baru, undang-undang dan bahkan juga kekuatan politik. Perdagangan obat ilegal memegang peranan vital bagi organisasi kejahatan (UNODC, 2017; Lampe, 2015).

PBB melalui unit kerjanya, UNODC, merilis angka prevalensi pengguna napza di dunia setelah 2010 sampai 2014 stagnan di 5,2\% dari populasi penduduk dunia dengan angka mortalitas 190.000 jiwa setiap tahunnya, dimana mayoritas disebabkan penggunaan golongan opioid (UNODC, 2016; UNODC, 2017). Hasil riset kolaborasi BNN bersama Pusat Penelitian Kesehatan Universitas Indonesia (Puslitkes UI) tahun 2014 menunjukkan sebanyak $27.32 \%$ pengguna napza berasal dari komunitas pelajar (> 15 tahun) dan mahasiswa dengan total angka pengguna napza di Indonesia hampir mencapai 6 juta orang dan menewaskan 15 ribu jiwa orang setiap tahunnya (https://bnn.go.id/).

Deklarasi Aksi Nasional Pemberantasan Obat Ilegal dan Penyalahgunaan Obat pada Oktober 2017 dilatarbelakangi eskalasi kasus peredaran obat ilegal dan penyalahgunaan obat yang bahkan telah merenggut korban jiwa dari anak usia pendidikan Sekolah Dasar (SD) (http://setkab.go.id). Kasus anak SD yang tewas dan lebih dari 60 lainnya mengalami gangguan jiwa akibat tablet PCC di Kota Kendari, kasus siswa menjadi kurir narkoba di Kota Depok dan yang terbaru bulan Februari tahun 2018 di Kota Semarang ditemukan sabu dalam kemasan permen serta berbagai kasus lainnya telah membuktikan bahwa para pengedar obat ilegal telah menjadikan anak usia sekolah sebagai domain pasar yang potensial.

Tindakan preventif berupa kegiatan Kominikasi, Informasi dan Edukasi (KIE) yang diselenggarakan oleh Badan Pengawas Obat dan Makanan (BPOM) dalam memberantas peredaran obat ilegal dan penyalahgunaan obat pada komunitas SD merupakan hal yang sangat esensial. Diperlukan kolaborasi dari akademisi dan profesional untuk membuat suatu inovasi yang efektif dan efisien serta riil dalam meningkatkan pengetahuan anti penyalahgunaan obat pada komunitas siswa SD.

Berdasarkan paparan di atas, peneliti, di bawah supervisi pihak akademisi Institut Teknologi Bandung (ITB) dan pihak profesional Balai 
Pengawas Obat dan Makanan Di Palu (Balai POM Di Palu), telah merancang inovasi berupa edukasi anti penyalahgunaan obat melalui media kartu kuartet seperti pada gambar 1 dan 2. Selanjutnya peneliti melakukan penelitian yang bertujuan untuk mengetahui pengaruh edukasi tersebut terhadap pengetahuan anti penyalahgunaan obat siswa kelas lima SD di Kota Palu.

\section{METODE PENELITIAN}

\section{Rancangan Penelitian}

Jenis penelitian yang digunakan pada penelitian ini adalah preexperimental design dengan rancangan one group pretest-posttest. Variabel bebas dalam penelitian ini ialah edukasi anti penyalahgunaan obat melalui media kartu kuartet dan variabel terikatnya adalah pengetahuan anti penyalahgunaan obat siswa kelas lima SD di Kota Palu. Teknik pengambilan sampel dilakukan secara Purposive Sampling (Notoatmodjo, 2010).

\section{Populasi dan Sampel}

Populasi SD dalam penelitian ini adalah SD sederajat yang berlokasi di Kota Palu dan populasi siswa SD adalah siswa kelas lima dari tiga SD yang terpilih dan mengikuti serangkaian perlakuan edukasi dari peneliti. Sampel SD dan siswa merupakan SD dan siswa yang telah memenuhi kriteria inklusi sebagai berikut; sampel SD merupakan SD yang mewakili salah satu rangking yang ditetapkan peneliti berdasarkan hasil Cerdas Cermat BPOM Palu tingkat SD sederajat tahun 2017. Sampel siswa kelas lima merupakan responden dengan perubahan pengetahuan terbaik diantara populasi. Kriteria eksklusi dalam penelitian ini ialah SD maupun Siswa mengundurkan diri dari penelitian karena sesuatu hal. Penentuan besar sampel menggunakan rumus Slovin dengan presisi mutlak $10 \%$.

\section{Pengolahan Data}

Penilaian terhadap hasil pengisian kuesioner yang sebelumnya telah melalui uji validitas dan uji reliabilitas menggunakan skala Guttman. Analisis univariat dilakukan untuk mendeskripsikan variabel yang diteliti yakni nilai maksimal, nilai minimal, dan nilai rata-rata dari data pengetahuan anti penyalahgunaan obat para siswa yang diperoleh dengan menggunakan program IBM SPSS statistic 20. Analisis bivariat dilakukan untuk menganalisis ada tidaknya pengaruh edukasi melalui media kartu kuartet terhadap pengetahuan anti penyalahgunaan obat siswa kelas lima SD di Kota Palu. Analisis data meliputi uji normalitas dan uji analisis lanjutan baik itu analisis uji $\mathrm{T}$ berpasangan maupun analisis Wilcoxon.

\section{HASIL DAN PEMBAHASAN}

Data pretest dan posttest dari responden dikumpulkan dan diolah dengan analisis statistik yang sesuai. Hasil analisis uji Wilcoxon pada sampel siswa kelas lima dari seluruh SD menunjukkan nilai signifikansi sebesar $\mathrm{p} \leq 0,001$ seperti yang terdapat pada tabel 1 . Hasil analisis uji $\mathrm{T}$ berpasanganpada data pengetahuan siswa kelas lima dari SD B menunjukkan nilai signifikansi sebesar 0,005 seperti pada tabel 2. Hasil analisis uji $\mathrm{T}$ berpasangan pada data pengetahuan siswa kelas lima dari SD C menunjukkan nilai signifikansi sebesar $\mathrm{p} \leq 0,001$ seperti pada tabel 3. Nilai signifikansi dari SD B, SD C serta ke-3 SD secara simultan menunjukkan angka lebih kecil dari nilai $\alpha=0,05$. Hal tersebut menunjukkan hipotesis diterima yakni ada pengaruh edukasi anti penyalahgunaan obat melalui media kartu kuartet terhadap pengetahuan anti penyalahgunaan obat siswa kelas lima dari SD B, SD C serta ke-3 SD secara simultan.

Fenomena di atas konsisten dengan penelitian yang dilakukan oleh beberapa peneliti sebelumnya. Hesditiana (2014) memaparkan hasil penelitian bahwa terjadi peningkatan pengetahuan gizi pada siswa SD setelah mengikuti edukasi melalui media kreatif yang diberikan oleh peneliti. Selaras dengan yang ditemukan oleh Garris dkk (2002) bahwa pemberian permainan pada pelajar dalam proses pembelajaran meningkatkan jumlah the motivated learner dalam kelas. The motivated learner dapat diidentifikasi dari antusiasme serta fokus mereka selama mengikuti proses pembelajaran. Kedua hal tersebut ditemukan pada sampel penelitian siswa kelas lima SD di Kota Palu.

Penelitian Grady dkk (2013) menegaskan fakta bahwa antusiasme para pelajar yang dimunculkan oleh permainan sebagai pengenalan awal suatu topik pembelajaran terbukti meningkatkan nilai rata-rata pelajar saat ujian secara signifikan.Fenomena ini turut didukung dengan fakta yang diungkapkan oleh Rupini dan Nandagopal (2015) yang meneliti pengaruh keterlibatan indera terhadap zona konvergensi multisensor pada otak. Peneliti mengemukakan bahwa keterlibatan interaksi jumlah indera terhadap suatu benda akan selaras dengan kemampuan otak dalam membuat persepsi tentang benda tersebut. Saat siswa memainkan media 
kartu kuartet, indera penglihatan, pendengaran, sentuhan dan pengucapan dari siswa akan terlibat, lebih lanjut hal ini akan memudahkan otak siswa dalam membuat memori dari pengalaman bermain kartu kuartet. Hal ini menjelaskan keberhasilan pengaruh edukasi melalui media kartu kuartet terhadap pengetahuan siswa kelas lima dari SD B, C dan ke-3 SD secara simultan.

Hasil uji $\mathrm{T}$ berpasangan pada responden siswa kelas lima dari SD $\mathrm{K}$ menunjukkan nilai signifikansi sebesar 0,149 seperti pada tabel 4. Nilai signifikansi tersebut lebih besar dari nilai $\alpha=0,05$. Berbeda dengan fenomena sebelumnya, nilai signifikansi pada SD K menunjukkan bahwa edukasi anti penyalahgunaan obat melalui media kartu kuartet tidak berpengaruh terhadap pengetahuan anti penyalahgunaan obat siswa kelas lima dari SD K.

Hal tersebut kontradiktif dengan pembahasan fenomena pengaruh edukasi anti penyalahgunaan obat melalui media kartu kuartet terhadap pengetahuan anti penyalahgunaan obat siswa kelas lima SD B, SD C dan pada seluruh SD sebelumnya. Fenomena ini dapat dijelaskan karena perbedaan tingkat ranking.Rangking bisa diasumsikan sebagai indikator kemampuan kognitif rata-rata siswa di SD terkait.Hal ini sesuai dengan hasil penelitian yang dilakukan oleh Süß dan Kretzschmar (2018) yang mengemukakan fakta bahwa kemampuan kognitif yang dimiliki oleh siswa adalah prediktor substansial dalam menyelesaikan masalah yang dihadapi siswa tersebut.Perbedaan kemampuan kognitif rata-rata inilah yang kemudian menjadikan hasil pemberian edukasi pada siswa SD K tidak sebaik dengan hasil pemberian edukasi pada siswa dari kedua SD sebelumnya yang memiliki populasi siswa dengan kemampuan kognitif yang lebih baik.

Fenomena yang terjadi pada SD $\mathrm{K}$ dapat dipertegas dengan temuan peneliti saat memberikan edukasi yaitu kemampuan membaca pada beberapa siswa kelas lima SD K kurang baik. Pengaruh temuan tersebut dalam hasil penelitian dapat dijelaskan dengan fakta yang diungkapkan Creighton dan Szymkowiak (2014) bahwa edukasi menggunakan permainan yang bersifat kooperatif akan meningkatkan nilai evaluasi para siswa. Kemampuan membaca yang kurang baik pada beberapa siswa SD K menyebabkan karakter kooperatif dari media kartu kuartet tidak berjalan dengan baik pada beberapa kelompok bermain. Karakter kooperatif pada media kartu kuartet berupa kerja sama antara pemain satu dengan pemain yang lain dalam menebak subtema kartu kuartet yang ingin mereka kumpulkan menjadi satu set tema lengkap. Ketika dalam suatu kelompok bermain terdapat satu atau lebih pemain yang memiliki kemampuan membaca yang kurang baik, pemain lain terpaksa harus menggunakan cara lain untuk mengumpulkan set tema lengkap. Para pemain tidak membaca tema utama melainkan hanya menyebut angka tema dan saling menebak empat subtema dari tema tersebut. Hal ini membuat informasi penting pada tema terlewat begitu saja tanpa terekam di otak para siswa kelas lima SD K dalam kelompok bermain tersebut.

Tabel 1. Deskripsi data pengetahuan anti penyalahgunaan obat siswa kelas lima SD B, C dan K sebelum dan setelah edukasi

\begin{tabular}{|c|c|c|}
\hline \multirow[t]{2}{*}{ Jenis data } & \multicolumn{2}{|c|}{ Nilai data } \\
\hline & Pretest & Posttest \\
\hline Nilai maksimal & 21 & 21 \\
\hline Nilai minimal & 9 & 8 \\
\hline Mean ideal & 15,000 & 14,500 \\
\hline SD ideal & 2,000 & 2,167 \\
\hline $\begin{array}{l}\text { Responden } \\
\text { kategori baik }\end{array}$ & $43,94 \%$ & $63,64 \%$ \\
\hline $\begin{array}{l}\text { Responden } \\
\text { kategori sedang }\end{array}$ & $37,88 \%$ & $22,73 \%$ \\
\hline $\begin{array}{l}\text { Responden } \\
\text { kategori kurang }\end{array}$ & $18,18 \%$ & $13,63 \%$ \\
\hline Nilai normalitas ${ }^{\mathrm{c}}$ & 0,055 & 0,001 \\
\hline Nilai Signifikansi $^{d}$ & \multicolumn{2}{|c|}{$\mathrm{p} \leq 0,001$} \\
\hline Negative Ranks ${ }^{\mathrm{e}}$ & \multicolumn{2}{|c|}{12} \\
\hline Positive Ranks ${ }^{\mathrm{f}}$ & \multicolumn{2}{|c|}{42} \\
\hline Ties $^{\mathrm{g}}$ & \multicolumn{2}{|c|}{12} \\
\hline \multicolumn{3}{|c|}{$\mathrm{c}=$ Nilai Kolmogorov Smirnov $(\alpha=0,050)$} \\
\hline \multicolumn{3}{|c|}{$\mathrm{d}=$ Nilai Wilcoxon Signed Rank Test $(\alpha=0,050)$} \\
\hline \multicolumn{3}{|c|}{$\mathrm{e}=$ Posttest $<$ Pretest } \\
\hline \multicolumn{3}{|c|}{$\mathrm{f}=$ Posttest $>$ Pretest } \\
\hline \multicolumn{3}{|c|}{$\mathrm{g}=$ Posttest $=$ Pretest } \\
\hline
\end{tabular}

Tabel 2. Deskripsi data pengetahuan anti penyalahgunaan obat siswa kelas lima SD B sebelum dan setelah edukasi

\begin{tabular}{lcc}
\hline \multirow{2}{*}{ Jenis data } & \multicolumn{2}{c}{ Nilai data } \\
\cline { 2 - 3 } Nilai maksimal & Pretest & Posttest \\
Nilai minimal & 21 & 21 \\
Mean ideal & 14 & 17 \\
SD ideal & 1,1600 & 19,000 \\
Responden & $41,18 \%$ & 0,667 \\
kategori baik & & $52,94 \%$ \\
$\begin{array}{l}\text { Responden } \\
\text { kategori sedang }\end{array}$ & $47,06 \%$ & $29,41 \%$ \\
$\begin{array}{l}\text { Responden } \\
\text { kategori kurang }\end{array}$ & $11,76 \%$ & $17,65 \%$ \\
$\begin{array}{l}\text { Nilai normalitas } \\
\text { a }\end{array}$ & 0,211 & \\
Nilai Signifikansi & & \\
\hline
\end{tabular}


Tabel 3. Deskripsi data pengetahuan anti penyalahgunaan obat siswa kelas lima SD C sebelum dan setelah edukasi

\begin{tabular}{lcc}
\hline \multirow{2}{*}{ Jenis data } & \multicolumn{2}{c}{ Nilai data } \\
\cline { 2 - 3 } & Pretest & Posttest \\
\hline Nilai maksimal & 21 & 21 \\
Nilai minimal & 10 & 13 \\
Mean ideal & 15,500 & 17,000 \\
SD ideal & 1,833 & 1,333 \\
$\begin{array}{l}\text { Responden } \\
\text { kategori baik }\end{array}$ & $26,92 \%$ & $38,46 \%$ \\
$\begin{array}{l}\text { Responden } \\
\text { kategori sedang }\end{array}$ & $53,85 \%$ & $42,31 \%$ \\
$\begin{array}{l}\text { Responden } \\
\text { kategori kurang }\end{array}$ & $19,23 \%$ & $19,23 \%$ \\
$\begin{array}{l}\text { Nilai normalitas } \\
\text { a }\end{array}$ & \multicolumn{2}{c}{0,474} \\
\hline
\end{tabular}

Tabel 4. Deskripsi data pengetahuan anti penyalahgunaan obat siswa kelas lima SD K sebelum dan setelah edukasi

\begin{tabular}{|c|c|c|}
\hline \multirow[t]{2}{*}{ Jenis data } & \multicolumn{2}{|c|}{ Nilai data } \\
\hline & Pretest & Posttest \\
\hline Nilai maksimal & 19 & 20 \\
\hline Nilai minimal & 9 & 8 \\
\hline Mean ideal & 14,000 & 14,000 \\
\hline SD ideal & 1,667 & 2,000 \\
\hline $\begin{array}{l}\text { Responden } \\
\text { kategori baik }\end{array}$ & $21,74 \%$ & $34,78 \%$ \\
\hline $\begin{array}{l}\text { Responden } \\
\text { kategori sedang }\end{array}$ & $43,48 \%$ & $39,13 \%$ \\
\hline $\begin{array}{l}\text { Responden } \\
\text { kategori kurang }\end{array}$ & $34,78 \%$ & $26,09 \%$ \\
\hline $\begin{array}{l}\text { Nilai normalitas }{ }^{\text {a }} \\
\text { Nilai signifikansi }\end{array}$ & \multicolumn{2}{|c|}{0,149} \\
\hline $\begin{array}{l}\mathrm{a}=\text { Nilai Shapiro } \\
\mathrm{b}=\text { Nilai uji T ber }\end{array}$ & $\begin{array}{l}=0,050 \\
(\alpha=0\end{array}$ & \\
\hline
\end{tabular}

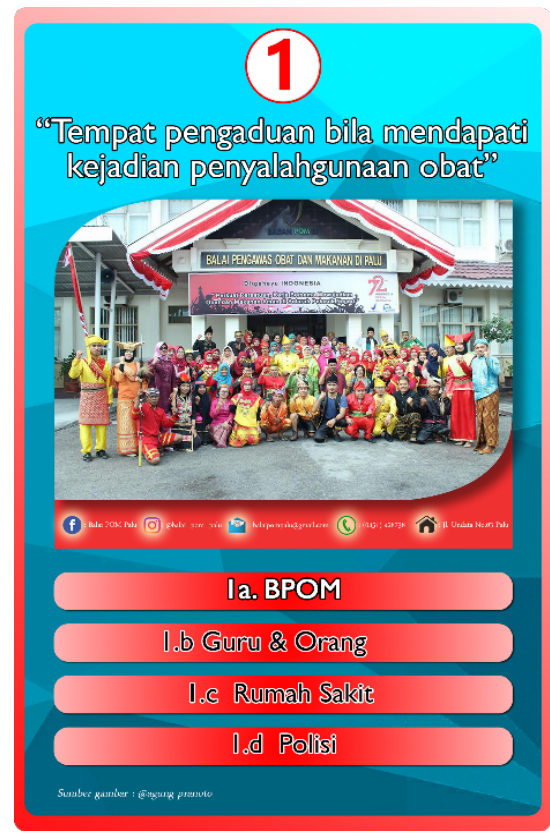

Gambar 1. Kartu kuartet anti penyalahgunaan obat untuk siswa sekolah dasar (tampak depan)

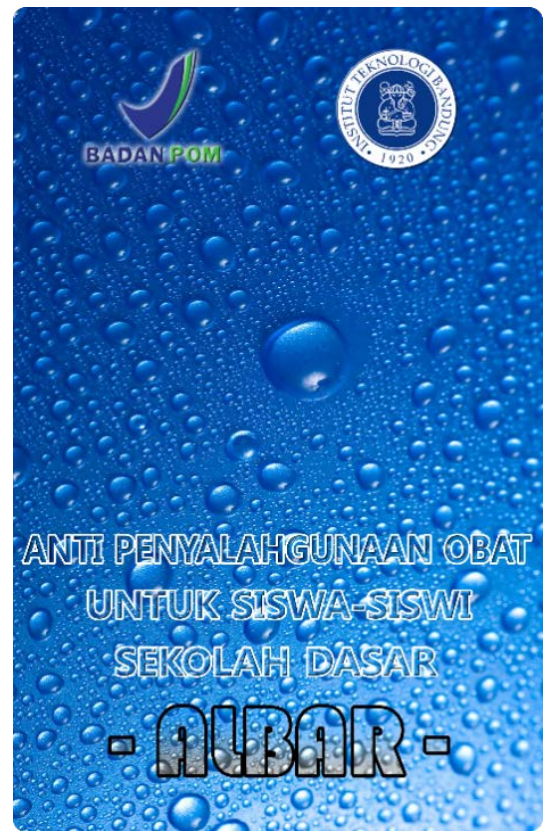

Gambar 2. Kartu kuartet anti penyalahgunaan obat untuk siswa sekolah dasar (tampak belakang)

\section{KESIMPULAN}

Edukasi anti penyalahgunaan obat melalui media kartu kuartet memberi pengaruh terhadap pengetahuan anti penyalahgunaan obat siswa kelas limaperwakilan SD ranking baik dan cukup baik sedangkan pada siswa kelas lima perwakilan SD ranking kurang baik, edukasi tersebut tidak memberi 
pengaruh terhadap pengetahuan anti penyalahgunaan obat mereka. Setelah data pengetahuan sampel dari seluruh SD dikumpulkan dan dianalisis, hasil menunjukkan ada pengaruh edukasi terhadap pengetahuan siswa kelas lima SD di Kota Palu.

\section{UCAPAN TERIMAKASIH}

Peneliti mengucapkan rasa terima kasih yang begitu besar kepada Bapak I Ketut Adnyana dan Ibu Pratiwi Wikaningtyas yang telah membimbing peneliti dari awal hingga akhir penelitian, Kepada Bapak Safriansyah selaku Kepala Balai POM Di Palu serta seluruh rekan BPOM Di Palu yang telah membantu hingga pelaksanaan penelitian dapat berjalan dengan baik. Kepada instansi kami, Badan Pengawas Obat dan Makanan, yang telah membiayai seluruh proses pendidikan dan penelitian. Kepada Orang tua, Istri, Anak-anak dan Saudara, Fartoks 2017 yang telah bersedia mengarungi waktu kebersamaan bersama peneliti selama penelitian berjalan.

\section{DAFTAR PUSTAKA}

Creighton, S., \& Szymkowiak, A. (2014).The effects of cooperative and competitive games on classroom interaction frequencies. Procedia- Social and Behavioral Sciences, 140, 155-163.

Garris, R., Ahlers, R., \& Driskell, JE.(2002).Games, motivation, and learning: a research and practice model. Simulation Gaming, 33,441-467.

Grady, SE., Vest, KM., \& Todd, TJ.(2013). Student attitudes toward the use of games to promote learning in the large class room setting. Currents in pharmacy teaching and learning, 5, 263-268.

Hesditiana, AI. (2014).Manfaat edukasi gizi dengan media kartun terhadap pengetahuan tentang pedoman umum gizi seimbang (PUGS) pada siswa sekolah dasar di SD Muhammadiyah 16 Surakarta (Tugas akhir program studi), Universitas Muhammadiyah Surakarta, Indonesia.
Lampe, KV.(2015). Recent publications on organized crime.Publication Monitor of Trends Organ Crim Springer Science, 17, 1-11.

Notoatmodjo, S. (2010).Metodologi penelitian kesehatan.Rineka Cipta.

Pidato sambutan Presiden Republik Indonesia pada pencanangan aksi nasional pemberantasan obat ilegal dan penyalahgunaan obat.(2018, Januari). Diperoleh dari situs internet: http://setkab.go.id/sambutan-presiden-jokowidodo-pada-pencanangan-aksi-nasionalpemberantasan-obat-ilegal-danpenyalahgunaan-obat-rabu-3-oktober-2017pukul-0900-wib-di-bumi-perkemahancibubur-jakarta-timur/.

Profil pengguna narkoba di Indonesia tahun 2014.(2018, Februari). Diperoleh dari situs internet:

http://bnn.go.id/read/pressrelease/17912/cipta kan-apartemen-bersih-inner-city-dan-bnntandatangani-nota-kesepahaman-pencegahanperedaran-narkoba.

Rupini, RV.,\& Nandagopal, R. (2015).A Study on the Influence of Senses and the Effectiveness of Sensory Branding.J Psychiatry, 18, 236.

Süß,HM.,\& Kretzschmar, A. (2018).Impact of cognitive abilities and prior knowledge on complex problem solving performance empirical results and a plea for ecologically valid microworlds.Front. Psychol,9, 626.

United Nations Office on Drugs and Crime (2016). World drug report 2016. Vienna: United Nations Publication.

United Nations Office on Drugs and Crime (2017). World drug report 2017. Vienna: United Nations Publication. 